\author{
C. T. Hamel \\ J. Metzger \\ G. Curti \\ L. Degen \\ F. Harder \\ M. O. von Flüe
}

\section{lleocecal reservoir reconstruction after total mesorectal excision: functional results of the long-term follow-up}

Accepted: 31 March 2004

Published online: 27 May 2004

(C) Springer-Verlag 2004
C. T. Hamel ( $)$ L. Degen · F. Harder Department of Surgery, Kantonsspital, Basel University,

Spitalstrasse 21, 4031 Basel, Switzerland e-mail: cthamel@bluewin.ch

Tel.: +41-61-2657785

Fax: +41-61-2657250

J. Metzger · G. Curti · M. O. von Flüe Department of Surgery,

Kantonsspital,

Luzern, Switzerland

\begin{abstract}
Background: The aim of this study is to obtain functional results of the long-term follow-up after TME and ileocecal interposition as rectal replacement. Methods: The study included patients operated on between March 1993 and August 1997 who received an ileocecal interposition as rectal replacement. Follow-up was carried out 3 and 5 years postoperatively. For statistical analysis, the paired $t$-test, rank test (Wilcoxon), and chi-square or Fisher's exact test were applied; level of significance, $P<0.05$. Results: Fortyfour patients were included in the studies. Of these, five were not available and four patients could not be evaluated (dementia 1, radiation proctitis 1 , fistula 1 , pouchitis 1 ). Seventeen patients died during the observation period; 12 died of the
\end{abstract}

disease. Recurrence of the disorder occurred in 2 of 35 patients $(5.7 \%)$; 26 and 18 patients, 3 and 5 years postoperatively, respectively remained in the study. At 5 years, $78 \%$ of the patients were continent; mean stool frequency was $2.5 \pm 1.6$ per day. Conclusions: Functional results and subjective assessment of ileocecal interposition were constant at 3 and 5 years postoperatively. If construction of a colonic J-pouch is not possible due to lack of colonic length, especially after prior colonic resections, the ileocecal interpositional reservoir may offer an alternative to rectal replacement.

Keywords Rectal carcinoma $\cdot$ Rectal reconstruction - Functional results . Total mesorectal excision - Ileocecal interposition

\section{Introduction}

The construction of an ileocecal interpositional pouch has been employed successfully for coloanal reconstruction in resectable recurrence of metachronous low rectal cancer with intact sphincter function after previous colorectal resection [1]. The indication has consequently been extended to coloanal reconstruction after total mesorectal excision for primary mid and low rectal cancer. In this article we report the results on long-term morbidity and defecation ability after ileocecal interposition for rectal replacement, 3 and 5 years after the operation. Due to the natural course of the malignant disease itself, a number of patients died before the 3 or 5 year follow-up was due.

\section{Materials and methods}

Patients

Between March 1993 and August 1997, 41 patients with rectal cancer, between 2 and $8 \mathrm{~cm}$ above the dentate line, and 3 patients with another diagnosis (sarcoma 1, large adenoma 2), underwent total mesorectal excision and immediate reconstruction with an ileocecal interpositional reservoir (Fig. 1). The anastomosis was 0$2 \mathrm{~cm}$ above the dentate line.

\section{Follow-up}

Follow-up was performed 3 and 5 years after the operation according to the same protocol. Functional outcome was assessed by questionnaire: the number of bowel movements on a typical day; incontinence (gas, liquid or solid stool) during the day or night; 
Fig. 1 a Isolation of ileocecal segment, b rectal replacement

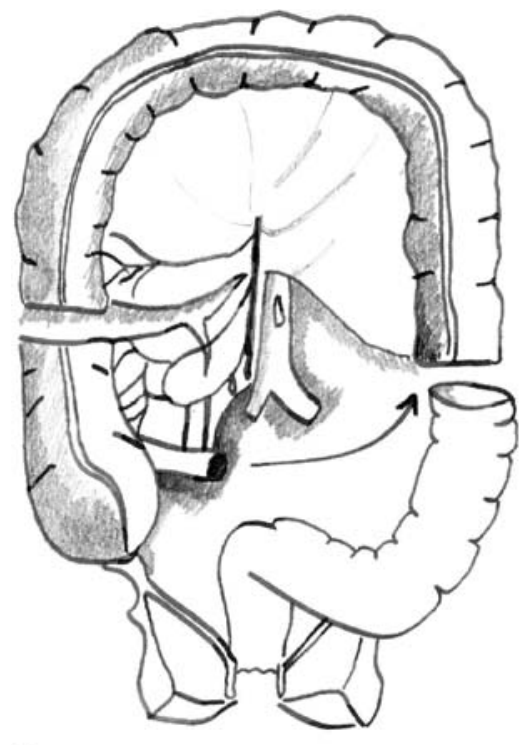

a

painful urge evacuation; and difficult evacuation; persistent urge to evacuate. Defecation ability was defined on the basis of continence, frequency, imperative urge, and completeness of evacuation (Table 2). Quality of life was assessed by the patient using a graded scale.

\section{Statistical methods}

Results are expressed as mean and standard deviation if normal distribution was shown and compared parametrically by a paired $t$-test. If there was no normal distribution, a rank test (Wilcoxon) was used and results expressed as median (range). Comparison of qualitative data was performed by chi-square or Fisher's exact test. Level of significance was $P<0.05$.

\section{Results}

Follow-up and survival

At 3 years postoperatively, 2 of 44 patients could not be contacted. This represents a data return rate of $96 \%$ (Table 1). Three patients had to be excluded from functional assessment ((radiation-proctitis 1 , pouch removal due to proctitis 1 , fistula 1 (permanent colostomy or ileostomy)). Thirteen of the 44 patients died, 10 of whom died of the disease. Three patients died of other causes (other carcinoma 2, myocardial infarction 1). Thus, only 26 patients could be functionally assessed 3 years after the ileocecal interposition.

Table 1 Follow-up

\begin{tabular}{|c|c|c|c|c|}
\hline Follow-up & 3 years & $n$ & 5 years & $n$ \\
\hline Number of initially operated patients & 44 & & 44 & \\
\hline Number of patients 3 and 5 years postoperatively & 44 & 44 & 44 & 44 \\
\hline Lost for follow-up & -2 & 42 & -5 & 39 \\
\hline Excluded & -3 & 39 & -4 & 35 \\
\hline Dementia & & & $(-1)$ & \\
\hline Radiation proctitis & $(-1)$ & & $(-1)$ & \\
\hline Exitus & -13 & 26 & -17 & 18 \\
\hline Death from disease & 10 & & 12 & \\
\hline Local recurrence & & & $2 / 35(5.7 \%)$ & \\
\hline Distant metastatic disease & & & $9 / 35(29 \%)$ & \\
\hline Other reasons & 3 & & 5 & \\
\hline Other carcinoma & (2) & & (3) & \\
\hline Coronary heart disease & (1) & & (2) & \\
\hline
\end{tabular}


At 5 years postoperatively, 5 of 44 patients were not available for follow-up. This represents a data return rate of $89 \%$. Four patients had to be excluded from functional assessment (dementia 1, radiation-proctitis 1 , pouch removal due to proctitis 1 , fistula 1 ). Seventeen patients died, 12 of whom died of the disease. Ten had distant metastatic disease $(29 \%)$ and two had local recurrence (5.9\%) (Table 1). Five patients died of other causes (other carcinoma 3, myocardial infarction 2). Eighteen patients could be functionally assessed 5 years after the initial operation.

Functional results

At 3 years nine patients (34\%) had absolutely no functional complaints, whereas seven patients (39\%) reported excellent functional results at 5 years $(P=0.89)$.

\section{Continence}

At 3 years 23 (88\%) of 26 patients were fully continent. One patient was incontinent for gas while two were incontinent for solid stool. At 5 years, 14 (77.8\%) of 18 patients were fully continent, whereas two $(11.1 \%)$ patients were incontinent for gas, one $(5.56 \%)$ patient for liquid stool, and one for solid stool. There was no statistical difference between the two follow-ups $(P=0.48)$.

\section{Stool frequency}

Mean stool frequency per day was 3.0 \pm 2.0 at 3 years and $2.5 \pm 1.6$ at 5 years. There was no statistical difference $(P=0.44)$.

\section{Fragmentation}

Multiple evacuations (fragmentation of defecation) were defined as the need to empty the neorectum two or more times within $1 \mathrm{~h}$. At 3 years postoperatively, 12 (46\%) patients had fragmentation of defecation, whereas at 5 years postoperatively this condition was reported by 10 (56\%) patients. The difference was not statistically significant $(P=0.76)$.

\section{Discrimination of gas and stool and urgency}

At 3 years $88 \%$ of the patients could discriminate gas from stools correctly. At 5 years this condition was mentioned by $83 \%$ of the patients $(P=1.00)$. Three $(12 \%)$ patients mentioned urgency after 3 years, whereas this was reported by three $(16.7 \%)$ patients after 5 years $(P=1.00)$.

\section{Soiling and use of sanitary pads}

Soiling was reported by $34.6 \%$ of the patients at 3 years and in $38.9 \%$ of the patients at 5 years postoperatively $(P=1.00)$. At 3 and 5 years postoperatively, 42 and $50 \%$ of the patients did not need sanitary pads for protection $(P=0.75)$.

\section{Subjective assessment}

The patients were asked about their personal assessment and quality of life after the operation. Three and 5 years after the operation 85 and $89 \%$ of the patients assessed the functional outcome of the operation in terms of defecation ability as good to very good $(P=1.0)$.

\section{Discussion}

Surgery on rectal carcinoma aims at a curative R0 resection with sphincter preservation and consecutive rectal replacement. Several methods have been described in the literature: Parks [2] proposed the straight coloanal anastomosis at the level of the dentate line. One of the factors limiting defecation quality most is defecation frequency (including nocturnal). After this type of reconstruction, patients complain about high defecation frequencies. The lack of a reservoir (36\% of the patients had more than three defecations per day) was discussed as the main reason for the so-called anterior resection syndrome. Furthermore, 29\% (21-34\%) of the patients complained about persisting evacuation problems (clustering). Patients often felt the urge to return to the toilet soon after defecation [3]; up to $15 \%$ of the patients reported this problem. Especially the sigmoid and descending colon with its small diameter may not be the best choice for rectal replacement.

Lazorthes and Parc [4, 5] introduced the colonic $J$-pouch to provide reservoir capacity in order to control these problems. In randomized trials, the colonic J-pouch yields a better functional outcome (lower stool frequency, safety of anastomosis) when compared to the straight coloanal anastomosis $[6,7]$. Joo et al. [8] showed that the functional superiority of the colonic J-pouch was greatest at 1 year after surgery. By 2 years, adaptation of the "straight" coloanal anastomosis yielded similar functional results. However, the almost fourfold reduction in anastomotic complications in the colonic J-pouch group reveals a second potential advantage of this technique. The majority of the patients with a colonic J-pouch were reported to have a daily frequency of less than three bowel 
movements. In several studies this reached statistical significance when compared to the straight anastomosis. Therefore the proponents of the colonic J-pouch claim that some of the superiority over the straight anastomosis lies in its improved continence.

Another problem occurring with the development of the colonic J-pouch is incomplete or split defecation. Numerous studies have shown that the price for reduced frequency might be incomplete evacuation. Three or more attempts are needed to pass one bowel movement [7, 913]. Both Parc et al. [5] and Berger et al. [14] identified this as a problem, with $25 \%$ of their patients requiring aids, e.g., suppositories, to overcome this. There is a wide range $(21-79 \%)$ of patients having this problem. One reason for incomplete evacuation may be electrophysiological changes in the neorectum. Electromyographic coloanal J-pouch recordings demonstrated a reduced electric activity with increased uncoordinated spike potentials and a decreased continuous electric response activity [15]. The loss of intrinsic and extrinsic, sympathetic and parsympathetic nerve supply to the mobilized left colon and the need for longitudinal transsection might explain these findings and may be one factor of incomplete evacuation. Another reason for incomplete evacuation is the size of the pouch itself. In a randomized setting, Hida et al. [16] looked at the ideal size of the pouch. A standardized $5-\mathrm{cm}$ colonic J-pouch was compared to a $10-\mathrm{cm}$ colonic J-pouch. Evacuation function in the $5-\mathrm{cm}$ colonic J-pouch group was significantly superior to that in the $10-\mathrm{cm}$ colonic J-pouch group. The $5-\mathrm{cm}$ colonic $\mathrm{J}$-pouch conferred an adequate reservoir function without compromising evacuation, a fact not yet documented, when we started the ileocecal interposition technique.

Other attempts to replace a rectal reservoir function include the simple side-to-end coloanal anastomosis and the coloplasty pouch, which was proposed by Z'graggen and Maurer in 1999 [17, 18] in a pig model. They concluded that the construction of the pouch is technically simpler than the colon J-pouch and the smaller capacity of the pouch seems to be sufficient for normal defecation. The same authors presented results for 41 humans in 2001. The authors concluded that the early functional outcome is favorable and can be compared to other colonic reservoirs [19]. Ho et al. presented a randomized, controlled trial comparing this technique to the colonic J-pouch [20]. In their study the authors found a higher incidence of anastomotic leaks in the coloplasty group $(15.9 \%, 7 / 44)$ compared to the colonic J-pouch group $(0 \%, 0 / 44)$. Seven percent were clinical and $9 \%$ were radiologic. In a nonrandomized study, an incidence of 5\% was reported [21]. Hallböök et al. [6] reported a randomized controlled trial comparing J-pouch with straight coloanal anastomosis. The J-pouch patients had significantly fewer clinical anastomotic leaks (2 vs. 15\%; $P=0.03)$. The lower incidence of anastomotic leak after J-pouch may be due to better proximal anastomotic blood supply, as shown by the laser Doppler technique [22]. The authors concluded that to date the colonic J-pouch remains the benchmark for routine use [20] (Table 2).

Another option using the same type of anastomosis like the colonic J-pouch is the side-to-end coloanal anastomosis. The blind end of $4 \mathrm{~cm}$ is supposed to act as a reservoir in this type of reconstruction. The main reason to advocate this technique was to overcome the problem of bowel lumen incongruence and to prevent anastomotic stricture [23]. In a randomized, controlled setting this technique was compared to the colonic J-pouch [24]. The authors concluded that both forms of reconstruction have similar surgical and technical results. Functional results in terms of stool frequency and urge were better in colonic J-pouch patients, especially in the early postoperative phase and the colonic J-pouch should be the reconstruction of choice for low and ultralow spincter, avoiding surgery of the rectum.

An alternative rectal reservoir can be formed using the ileocecal segment [1]. In this technique the excised rectum is replaced by an ileocecal interposition which forms the new reservoir based on an isolated ileocecal segment. The neurovascular pedicle remains intact and the colonic wall is not transected. This method appeared to be an attractive alternative means of rectal reconstruction.

Our data of an ileocecal interposition are comparable with the findings of the colonic J-Pouch. The mean stool frequency per day was $2.6 \pm 1.8$ at 5 years and $3.0 \pm 2.0$ at 3 years. There is no statistical difference between the two follow-ups. Multiple evacuations were reported in 54.5\% of the patients at 5 years postoperatively and in $43.4 \%$ of the patients at 3 years postoperatively. There might be a tendency towards more fragmentation over time, but there was no statistical significance when data were compared. The fragmentation of evacuation did not influence the subjective assessment of quality of life in our patients. An expected favorable influence of the intact neural supply on the evacuation process could not be demonstrated. The size of the reservoir itself and the consistency of the stool seem to be more important factors for determining evacuation.

Functional results and subjective assessment of ileocecal interposition are constant at 3 and 5 years postoperatively. If construction of a colonic J-pouch is not possible due to lack of colonic length, especially after prior colonic resections, the ileocecal interpositional reservoir may offer an alternative rectal replacement. Other indications include diverticular disease of the descending colon when a colonic J-pouch reconstruction is not suitable and a thickened mesentery which cannot be placed in a narrow pelvis. 
Table 2 Functional outcome

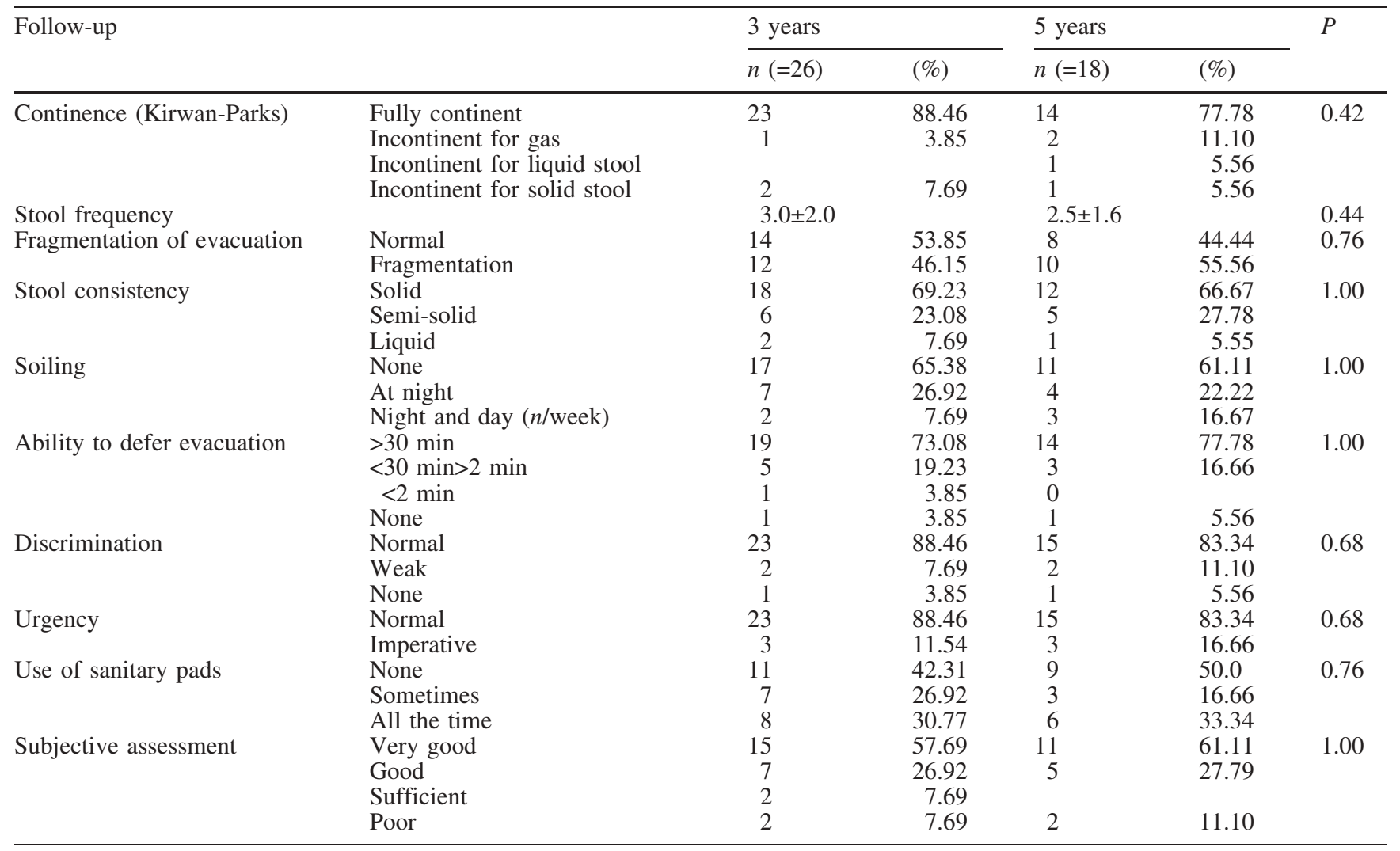

\section{Conclusion}

The ileocecal interpositional reservoir may offer another option to rectal replacement after total mesorectal resection, especially in situations when construction of a co- lonic J-pouch (the gold standard) is not possible. Functional results and subjective assessment of ileocecal interposition are constant at 3 and 5 years postoperatively and are comparable to other types of rectal reconstruction.

\section{References}

1. von Flüe M, Harder F (1994) A new technique for pouch-anal reconstruction after total mesorectal excision. Dis Colon Rectum 37:1160-1162

2. Parks AG (1972) Transanal technique in low rectal anastomosis. Proc R Soc Med 65:975-976

3. Paty BP, Enker WE, Cohen AM et al (1994) Long-term functional results of coloanal anastomosis for rectal cancer. Am J Surg 167:90-95

4. Lazorthes F, Fages P, Chiotasso P et al (1986) Resection of the rectum with construction of a colonic reservoir and colo-anal anastomosis for carcinoma of the rectum. Br J Surg 73:136-138

5. Parc R, Tiret E, Frileux P et al (1986) Resection and colo-anal anastomosis with colonic reservoir for rectal carcinoma. Br J Surg 73:139-141
6. Hallböök O, Pahlmann L, Krog M et al (1996) Randomized comparison of straight and colonic $\mathrm{J}$ pouch anastomosis after low anterior resection. Ann Surg 224:58-65

7. Ho YH, Tan M, Seow-Choen F (1986) Prospective randomized controlled study of clinical function and anorectal physiology after low anterior resection: comparison of straight and colonic J pouch anastomoses. Br J Surg 83:978980

8. Joo JS, Latulippe JF, Alabaz O et al (1998) Long-term functional evaluation of straight coloanal anastomosis and colonic J-pouch: is the functional superiority of colonic J-pouch sustained? Dis Colon Rectum 41:740-746
9. Nicholls RJ, Lubowski DZ, Donaldson DR (1988) Comparison of colonic reservoir and straight colo-anal reconstruction after rectal excision. Br J Surg 75:318-320

10. Kusunoki M, Shoji Y, Yanagi $\mathrm{H}$ et al (1991) Function after anoabdominal rectal resection and colonic $\mathrm{J}$ pouchanal anastomosis. Br J Surg 78:14341438

11. Pelissier EP, Blum D, Bachour A et al (1992) Functional results of coloanal anastomosis with reservoir. Dis Colon Rectum 35:843-846

12. Romanos J, Stebbing JF, Smiligin Humphreys MM et al (1996) Ambulatory manometric examination in patients with a colonic $J$ pouch and in normal controls. Br J Surg 83:17441746 
13. Kusunoki M, Okamoto T, Yoshikawa H et al (1996) Defecographic assessment after colonic J pouch-anal anastomosis. Surg Today 26:971-974

14. Berger A, Tiret E, Parc R et al (1992) Excision of the rectum with colonic J pouch-anal anastomosis for adenocarcinoma of the low and mid rectum. World J Surg 16:470-477

15. Hildebrandt U, Zuther T, Lindemann W et al (1993) Elektromyographic function of colonic J pouch. In: Becker HD, Berger H, Hartel W (eds) Chirurgisches forum $1993 \mathrm{~F}$. Experim. Klinische Forschung. Springer, Berlin Heidelberg New York, pp 127-131

16. Hida J, Yasutomi M, Fujimoto K et al (1996) Functional outcome after low anterior resection with low anastomosis for rectal cancer using the colonic J-pouch. Prospective randomized study for determination of optimum pouch size. Dis Colon Rectum 39:986-991
17. Z'graggen K, Maurer CA, Mettler D et al (1999) A novel colon pouch and its comparison with a straight coloanal and colon J-pouch-anal anastomosis: preliminary results in pigs. Surgery 125:105-112

18. Maurer CA, Z'graggen K, Zimmermann W et al (1999) Experimental study of neorectal physiology after formation of a transverse coloplasty pouch. Br J Surg 86:1451-1458

19. Z'graggen K, Maurer CA, Birrer S et al (2001) A new surgical concept for rectal replacement after low anterior resection: the transverse coloplasty pouch. Ann Surg 234:780-785; discussion 785-787

20. Ho YH, Brown S, Heah SM, Tsang C et al (2002) Comparison of J-pouch and coloplasty pouch for low rectal cancers: a randomized, controlled trial investigating functional results and comparative anastomotic leak rates. Ann Surg 236:49-55
21. Mantyh CR, Hull TL, Fazio VW (2001) Coloplasty in low colorectal anastomosis: manometric and functional comparison with straight and colonic J-pouch anastomosis. Dis Colon Rectum 44:37-42

22. Hallböök O, Johansson K, Sjodahl R (1996) Laser Doppler blood flow measurement in rectal resection for carcinoma-comparison between the straight and colonic J pouch reconstruction. Br J Surg 83:389-392

23. Baker JW (1950) Low end to side rectosigmoid anstomosis: description of technique. Arch Surg 61:143-145

24. Huber FT, Herter B, Siewert JR (1999) Colonic pouch vs side-to-end anastomosis in low anterior resection. Dis Colon Rectum 42:896-902 